\title{
Optimization of process parameters of medium carbon steel joints joined by MIG welding using Taguchi method
}

\author{
Mehmet Şükrü Adin ${ }^{*}$, Bahattin İşcan \\ 'Department of Mechanical Engineering, Batman University, Batman, Turkey.
}

Orcid: M. Ş. Adin (0000-0002-2307-9669), B. İşcan (0000-0002-6100-1555)

\begin{abstract}
In this study, related to getting better obtain to the mechanical properties of medium carbon steel joints joined by MIG welding method using the Taguchi method welding groove were optimized. Grove angle $\left(60^{\circ}, 75^{\circ}\right.$ and $\left.90^{\circ}\right)$, current $(100 \mathrm{~A}, 110 \mathrm{~A}$ and $120 \mathrm{~A})$ and voltage $(25 \mathrm{~V}, 30 \mathrm{~V}$ and $35 \mathrm{~V})$ were used as welding parameters. The results showed that the highest tensile strength as $597.963 \mathrm{MPa}$ was obtained at groove angle $90^{\circ}$, current $120 \mathrm{~A}$ and voltage $30 \mathrm{~V}$, the lowest tensile strength was obtained as 395. $125 \mathrm{MPa}$. The highest elongation as II.55।\% was obtained at groove angle $90^{\circ}$, current I $20 \mathrm{~A}$ and voltage $30 \mathrm{~V}$, the lowest elongation was obtained as $8.354 \%$. In addition, it was observed that the changes in current and voltage values significantly affect the tensile strength and elongation values of the joints. According to ANOVA analyses, the most effective parameter on average tensile strength and elongation were determined to be groove angle $(62.75 \%$ and $75.58 \%$, respectively). Based on $\mathrm{S} / \mathrm{N}$ ratios, the optimal parameters for average tensile strength and elongation were determined $\mathrm{A} 3 \mathrm{~B} 3 \mathrm{C} 2$ factors.
\end{abstract}

Keywords: Optimization, Taguchi method, ANOVA, MIG welding, AISI I040, Tensile test

\section{Introduction}

In today's manufacturing industry, the need for highstrength and cost-effective metal joining is increasing day by day. In accordance with these growing needs and demands purposes, one of the leading methods is welding. Welding is the most common method used to obtain high-strength, reliable and low-cost metal joints [1-3]. Gas Metal Arc Welding (GMAW/MIG) is one of the most preferred methods of joining metals by welding. This welding method has many advantages such as optimum product cost, better surface quality, strength and reasonable production speed [4-6]. The Metal Inert Gas (MIG) welding process is known as GMAW. In this process, the heat of the electric arc is used to melt metallic components and the consumable electrode wire. During the process, the filler wire is continuously fed into the weld pool by the welding gun and thus the main materials are joined. Gas shielding (argon, carbon dioxide or various other gas mixtures) atmosphere is created around the welding zone to protect the weld deposit from contaminants [5-8].

Medium carbon steels such as AISI 1040 are used extensively in different industries due to their properties such as strength, wear resistance and high toughness. There- fore, they are used in a variety of industrial applications including crankshafts, light gears, worms, axles, bolts, connection rods, spindles and many other automotive, aerospace, petroleum and piping products $[9,10]$. Manufacturing complex parts using AISI 1040 steels without joints as a single component is a cumbersome task. Therefore, they are joined by welding [11].

The strength of the joints to be made by MIG welding method of this steel material is requested to be the highest. In accordance with this purpose, remarkable studies in the literature on joints made with MIG welding method were examined.

Amit Pal [12] investigated the effects of different welding parameters such as welding current $(\mathrm{A})$, voltage $(\mathrm{V})$ and filler wire rate on the tensile strength of medium carbon steel joints joined by MIG welding. In the study, Taguchi method is used to optimize the effects of parameters on weld quality. As a result of his study, he reported that the quality of the joints is affected by different welding factors such as welding voltage, current, filler wire rate and affects the results produced from the tensile test [12]. Utkarsh et al. [13] examined the highest tensile strength of St-37 steel joints joined by MIG welding. In the study, Taguchi Orthogonal array is used to optimize 
Table I. Chemical compositions.

\begin{tabular}{|c|c|c|c|c|c|c|c|c|c|}
\hline \multirow{2}{*}{ Material } & \multicolumn{9}{|c|}{ Elements of composition (wt. \%) } \\
\hline & C & Si & Mn & $\mathbf{P}, \mathbf{S}$ & $\mathbf{C r}$ & Mo & $\mathbf{N i}$ & $\mathrm{Cu}$ & $\mathrm{Fe}$ \\
\hline AISI I040 & $0.37-0.44$ & $0.10-0.40$ & $0.50-0.80$ & $\leq 0.045$ & 0.03 & 0.009 & 0.04 & 0.06 & Balanced \\
\hline
\end{tabular}

the effects of parameters on weld quality. Gas flow rate, current (I), Voltage (V), and welding speed parameters were used for the study. As a result of their studies, they stated that current and voltage have significant effects on tensile strength [13]. In a study performed by Narwadkar and Bhosle [14], the optimization of parameters such as gas flow rate, voltage and current in Fe410WA type steel joints joined by MIG welding was investigated using the Taguchi method. As a result of their study, they stated that gas flow rate, current and voltage have important effects on joints [14]. Sankar et al. [15] studied the effects of welding parameters such as welding voltage, current and gas flow rate on weld joints of AISI 310 steel joints joined by MIG welding. In the study, the Taguchi method was used to optimize the effects of the parameters. The results of their study showed that the welding current has significant effects on the welding process [15]. Kumar and Roy [16] examined the effects of different welding parameters such as welding voltage $(\mathrm{V})$, current $(\mathrm{A})$, filler wire rate on AISI 304 and low carbon steel joints joined by MIG welding. In the study, Taguchi method is used to optimize the effects of parameters on weld quality. As a result of their study, they reported that the quality of the joints is affected by many factors such as welding voltage, filler wire rate and current [16]. Moghaddam et al. [17] investigated the MIG process to optimize the weld seam geometry and heat affected zone of SA387 steel plates. In the study, the Taguchi method was used to optimize the effects of parameters on the weld quality. As a result of their studies, they stated that welding current, voltage and bevel angle have significant effects on welding quality [17]. In a study performed by Arya et al. [18], they stated that the highest tensile strength was achieved by using the Taguchi method in alloy steel joints joined by MIG welding. As a result of their review, they reported that welding speed is the most vital factor for tensile strength [18]. Patil and Waghmare [19] investigated on increasing the tensile strength of AISI 1030 steel joints joined by MIG welding. In the study, the Taguchi method was used to optimize the effects of parameters on the weld quality. As a result, they reported that the welding speed has a significant effect on the tensile strength [19]. Mishra et al. [20] studied the effects of welding parameters such as welding voltage, welding speed and welding current on penetration depth of AISI 1020 steel joints joined by MIG welding. In the study, the Taguchi method was used to optimize the effects of parameters on the weld quality. They reported that the optimum penetration depth was obtained [20].

The literature review revealed that many welding parameters such as voltage, current, gas flow rate, filler wire used for MIG welding significantly affect the mechanical properties. Therefore, it is necessary to optimize these parameters. In addition, it has proven that mechanically desired results are obtained when the welding parameters are optimized with the Taguchi method.

In this study, it was aimed to analyse the mechanical properties of AISI 1040 steel rod joints joined by MIG welding, and to optimize the input parameters with the help of Taguchi method to obtain good mechanical properties.

\section{Material and Method}

\section{I. Material, filler wire and welding parameters}

In this study, commercial material medium carbon steel AISI 1040 cylindrical rods were used. AISI 1040 steels have attracted attention due to their properties such as high strength, wear resistance, and toughness. Because of these properties, light gears, crankshafts, axles, worms, connecting rods, bolts, spindles, torsion bars and many other It is used in a variety of industrial applications including aerospace, automotive, petroleum and piping products $[9,10]$. The chemical compositions and mechanical properties of AISI 1040 used in the study are given in Table 1 and Table 2.

\begin{tabular}{rccc} 
Table 2. Mechanical properties. & & \\
\hline Material & $\begin{array}{c}\text { Tensile strength } \\
(\mathrm{MPa})\end{array}$ & $\begin{array}{c}\text { Yield strength } \\
(\mathrm{MPa})\end{array}$ & $\begin{array}{c}\text { Elongation } \\
(\%)\end{array}$ \\
AISI I040 & 666 & 358 & 22.7
\end{tabular}

In the study, ER70S-6 (AWS A5.18) filler wire was used for MIG welding. ER70S-6 filler wires are used with pure $\mathrm{CO}_{2}$ or a mixture of $\mathrm{Ar}$ and $\mathrm{CO}_{2}$ gases. It is a type of copper-coated steel welding. It provides higher strength and excellent welding properties [21]. It is widely used for welding metals [21-24]. These electrodes contain the highest combinations of deoxidizers in the form of manganese and silicon [24]. The diameter of filler wire used in MIG welding is $1.2 \mathrm{~mm}$. The chemical compositions and mechanical properties of ER70S-6 filler wire are given in Table 3, Table 4, respectively [22].

The parameters of the welding process are given in Table 5. In accordance with ASME Specifications (AWS A5.18), a mixture of $\operatorname{Ar}(95 \%)$ and $\mathrm{CO}_{2}(5 \%)$ was used as shielding gas to obtain quality welding [22]. All welding processes were performed at room temperature and $50 \pm 5$ $\%$ relative humidity. MIG welding was performed with Arctech Arc-450 welding machine. Before the welding 
Table 3. Chemical compositions of filler wire [22].

\begin{tabular}{|c|c|c|c|c|c|c|c|c|c|}
\hline \multirow{2}{*}{ Filler wire } & \multicolumn{9}{|c|}{ Elements of composition (wt. \%) } \\
\hline & C & Si & Mn & $\mathbf{P}$ & $\mathbf{S}$ & Mo, $\mathrm{Ni}, \mathrm{Cr}$ & V & $\mathrm{Cu}$ & $\mathbf{F e}$ \\
\hline ER70S-6 & $0.06-0.15$ & $0.80-1.15$ & $1.40-1.85$ & $\leq 0.025$ & $\leq 0.035$ & $\leq 0.15$ & $\leq 0.03$ & $\leq 0.5$ & Balanc. \\
\hline \multirow{2}{*}{\multicolumn{2}{|c|}{ Filler wire }} & \multicolumn{3}{|c|}{ (Minimum) } & \multicolumn{3}{|c|}{ (Minimum) } & \multicolumn{2}{|c|}{ (Minimum) } \\
\hline & & \multicolumn{3}{|c|}{ Tensile strength (MPa) } & \multicolumn{3}{|c|}{ Yield strength (MPa) } & \multicolumn{2}{|c|}{ Elongation (\%) } \\
\hline \multicolumn{3}{|c|}{ ER70S-6 } & \multicolumn{2}{|c|}{480} & \multicolumn{3}{|c|}{400} & \multicolumn{2}{|c|}{22} \\
\hline
\end{tabular}

Table 5. Welding parameters.

\begin{tabular}{|c|c|c|c|c|c|c|}
\hline \multirow{2}{*}{ Sample No } & \multirow{2}{*}{ Groove angle $\left(\alpha^{\circ}\right)$} & \multirow{2}{*}{ Welding technology } & \multicolumn{4}{|c|}{ Welding parameters } \\
\hline & & & Current $(\mathrm{A})$ & Voltage $(\mathrm{V})$ & Welding Speed $\left(\mathrm{mmxmin}^{-1}\right)$ & Gas flow rate $\left(\mathrm{kgxhr}^{-1}\right)$ \\
\hline SI & $60^{\circ}$ & MIG (GMAW) & 100 & 25 & 30 & 28 \\
\hline $\mathrm{S} 2$ & $60^{\circ}$ & MIG (GMAW) & 110 & 30 & 30 & 28 \\
\hline S3 & $60^{\circ}$ & MIG (GMAW) & 120 & 35 & 30 & 28 \\
\hline S4 & $75^{\circ}$ & MIG (GMAW) & 100 & 30 & 30 & 28 \\
\hline S5 & $75^{\circ}$ & MIG (GMAW) & 110 & 35 & 30 & 28 \\
\hline S6 & $75^{\circ}$ & MIG (GMAW) & 120 & 25 & 30 & 28 \\
\hline S7 & $90^{\circ}$ & MIG (GMAW) & 100 & 35 & 30 & 28 \\
\hline S8 & $90^{\circ}$ & MIG (GMAW) & 110 & 25 & 30 & 28 \\
\hline S9 & $90^{\circ}$ & MIG (GMAW) & 120 & 30 & 30 & 28 \\
\hline
\end{tabular}

process, the rods were carefully cleaned of external factors such as dirt and oil that could affect a quality weld [25].

AISI 1040 steel rods, $250 \mathrm{~mm}$ long and $20 \mathrm{~mm}$ diameter, were machined on a Computer Numerically Controlled (CNC) lathe to obtain the required shape and dimensions. All samples were prepared according to ASTM E8M standard [26]. The dimensions of the samples prepared for welding are given in Fig. 1.

In MIG welding processes, welding speed and gas flow rate were kept constant in order to clearly measure the differences in mechanical properties between the joints. The experimental methodology up to the preparation of the tensile samples is given in Fig. 2. For welding process, the surfaces of the samples were cleaned with a grinding machine for make ready the tensile test.

\subsection{Tensile testing}

The samples prepared according to the ASTM E8M standard were carefully cleaned again from external factors such as dirt, oil and rust before the tensile test.

Tensile tests were performed with a $250 \mathrm{kN}$ Shimadzu universal tester at room temperature, $50 \pm 5 \%$ humidity and $1 \mathrm{~mm} \times \mathrm{min}^{-1}$ crosshead speed [27]. The tensile testing machine used in the experimental study is shown in Fig. 3.

\subsection{Taguchi method}

In the manufacturing industry, thanks to the advancing technology, optimization techniques have been developed to determine the effect values of the factors used during

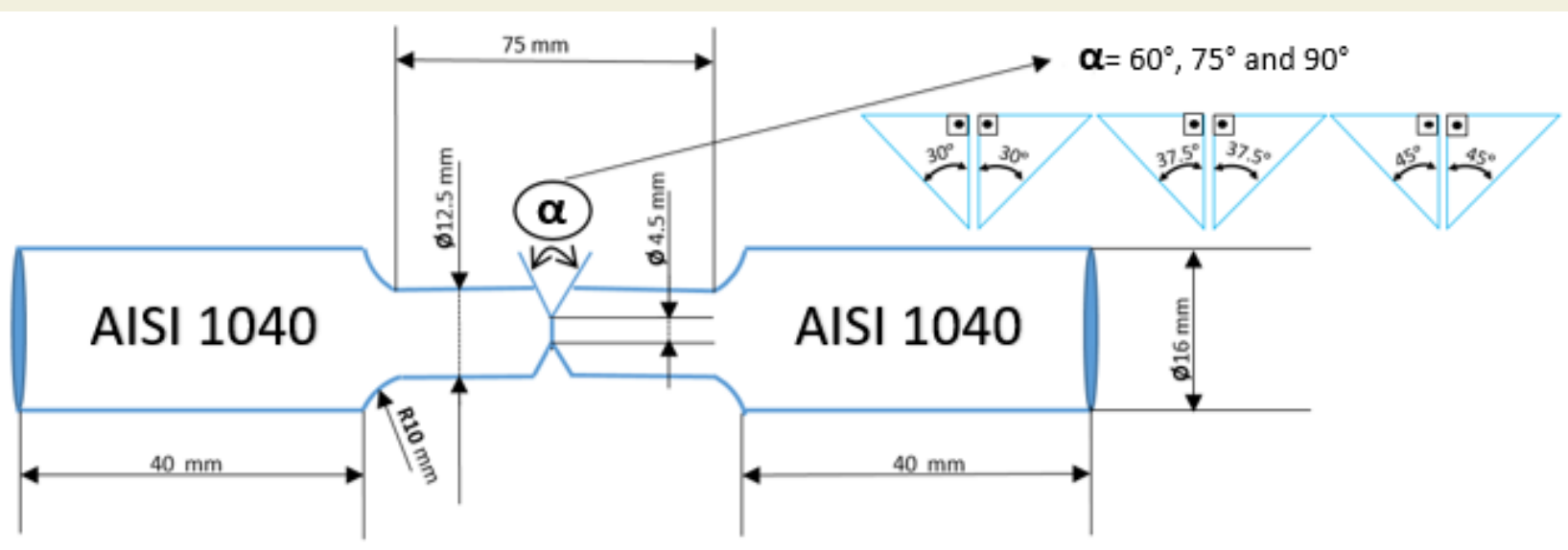

Figure 1. The dimensions of tensile test sample. 


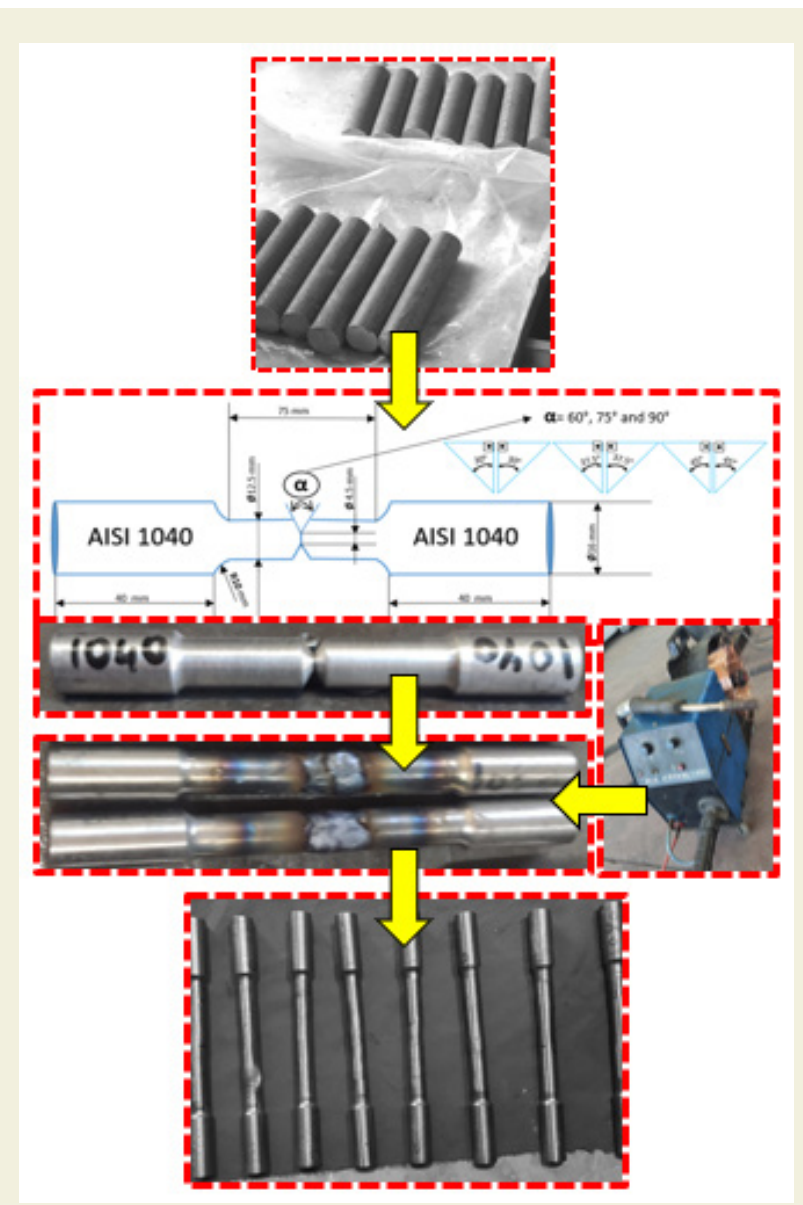

Figure 2. Experimental methodology.

product processing in order to determine the basic optimum parameters. The most prominent of these is the Taguchi optimization method. The Taguchi method is an optimization method and experimental design based on factor design, tolerance design and system design. In addition, it is used to determine the optimal parameters from different levels [4, 9, 28-32]. In the manufacturing industry, the time required for the product can be reduced by using the Taguchi method, thus reducing the costs and in-

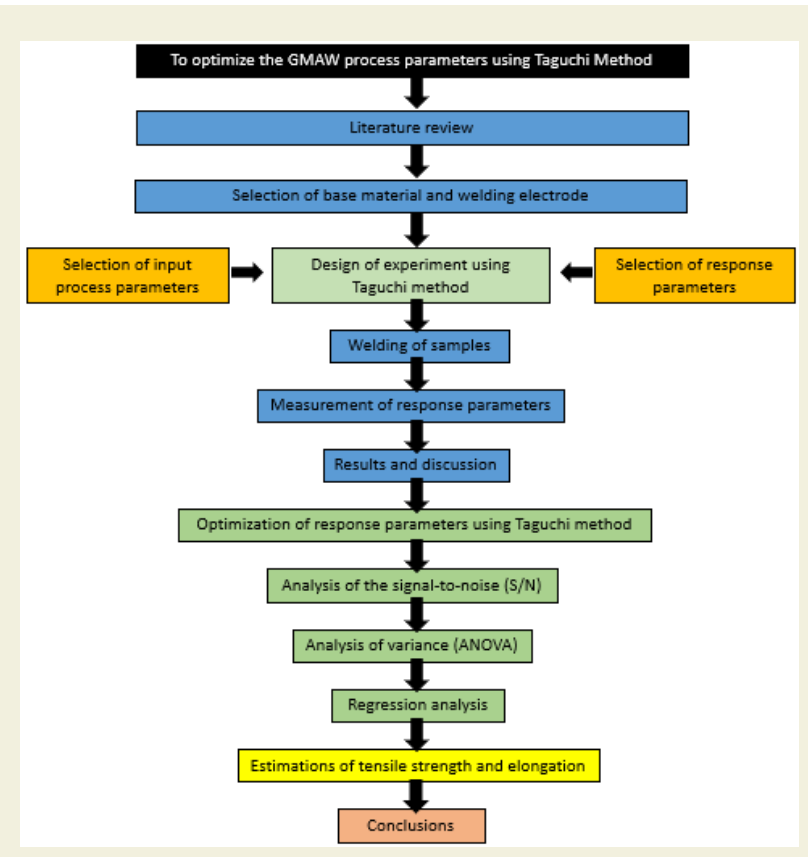

Figure 4. Stepwise experimental scheme.

creasing the profit rate of the business. In addition, thanks to the Taguchi method, it is possible to control for variables that cannot be explained in the conventional experimental design. In the Taguchi method, objective function values are converted into a signal-to-noise $(\mathrm{S} / \mathrm{N})$ ratio to measure the performance characteristics of control factor levels against these factors. The $\mathrm{S} / \mathrm{N}$ ratio is defined as the ratio of the desired signal to the undesired random noise value. In this way, it is used as an indicator for the quality characteristics of the experimental data $[28,31]$. In the test design, each combination of control factors for tensile strength and elongation were measured. The $\mathrm{S} / \mathrm{N}$ ratios were used to optimize control factors. For the calculation of $\mathrm{S} / \mathrm{N}$ ratios, depending on the characteristic type, the objective functions are given as "Larger is better". Here, the "Larger is better" function (see equation (1)) is used

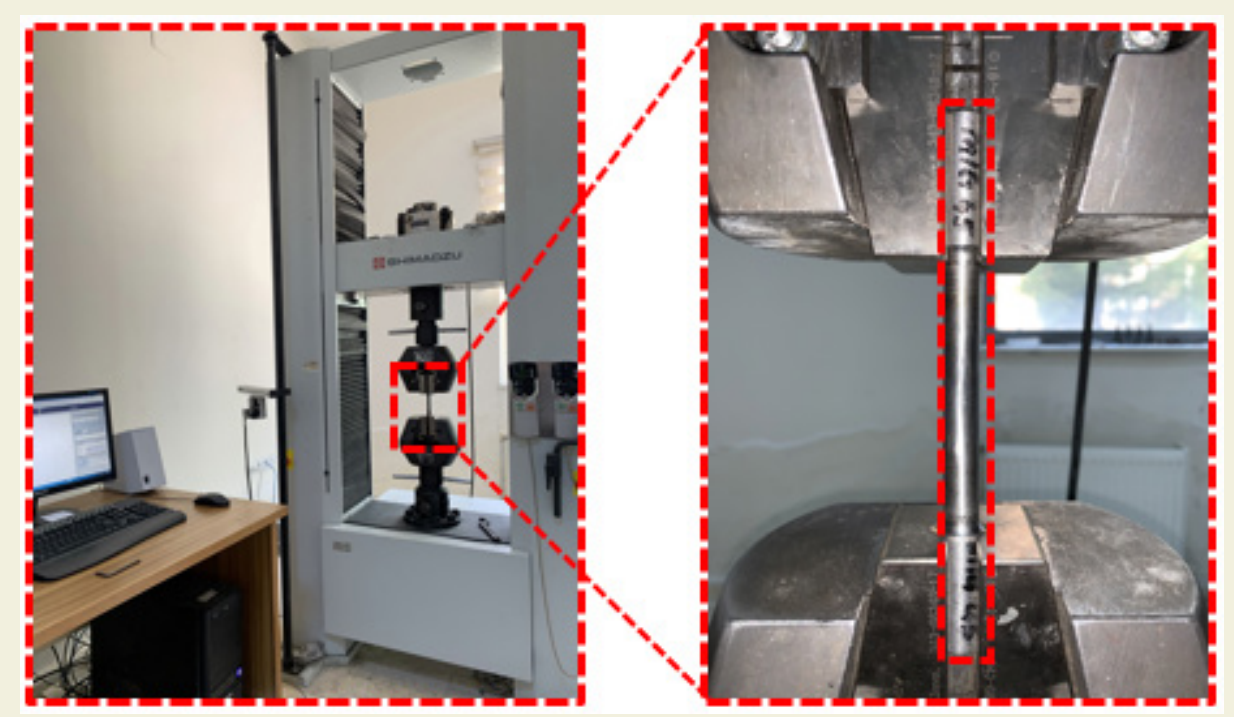

Figure 3. Tensile testing machine. 
because the tensile strength and elongation are intended to be higher.

The larger is better: $S / N=-10 \log \left(\frac{1}{n} \sum_{i=1}^{n} \frac{1}{y_{i}^{2}}\right)$

with $\boldsymbol{n}$ : Number of observations, $\boldsymbol{y}_{\boldsymbol{i}}: \boldsymbol{i}$-th number of observations and $S / N$ : Signal to noise ratio.

Stepwise experimental scheme of the present study is shown Fig.4.

\subsection{Parameters and levels}

The parameters and levels used in the experimental study are given in Table 6.

\begin{tabular}{|c|c|c|c|c|c|}
\hline Parameters & Symbols & Units & Level I & Level 2 & Level 3 \\
\hline Groove angle & $A$ & $\alpha^{\circ}$ & $60^{\circ}$ & $75^{\circ}$ & $90^{\circ}$ \\
\hline Current & B & Ampere (A) & 100 & 110 & 120 \\
\hline Voltage & C & Voltage (V) & 25 & 30 & 35 \\
\hline
\end{tabular}

The most suitable Taguchi orthogonal experiment design (L9) for this study was chosen based on these levels (Table 7).

\begin{tabular}{cccc}
\multicolumn{5}{l}{ Table 7. Taguchi orthogonal array design L9. } \\
\hline Exp. no & Factor A & Factor B & Factor C \\
\hline 1 & 1 & 1 & 1 \\
2 & 1 & 2 & 2 \\
3 & 1 & 3 & 3 \\
4 & 2 & 1 & 2 \\
5 & 2 & 2 & 3 \\
6 & 2 & 3 & 1 \\
7 & 3 & 1 & 3 \\
8 & 3 & 2 & 1 \\
9 & 3 & 3 & 2 \\
\hline
\end{tabular}

\section{Results and discussion}

\section{I. Tensile test results}

As can be seen in Table 8, Fig. 5 and Fig. 6, when the tensile test results of the joints joined by MIG welding are examined, the highest tensile strength as $597.963 \mathrm{MPa}$ was obtained at groove angle $90^{\circ}$, current $120 \mathrm{~A}$ and voltage $30 \mathrm{~V}$. In the tests, the lowest tensile strength was measured as $395.125 \mathrm{MPa}$. The results showed that the highest tensile strength was $51.33 \%$ higher than the lowest tensile strength value. In addition, the average tensile strength of joints welded by MIG welding was measured as 504.042 MPa. The Load- extension curves of joints joined by MIG welding are given in Fig. 5.

Table 8 and Fig. 6 show the effects of the groove angles of the joints on the tensile strength values. As can be seen in the Table 8, it has been observed that the tensile strength

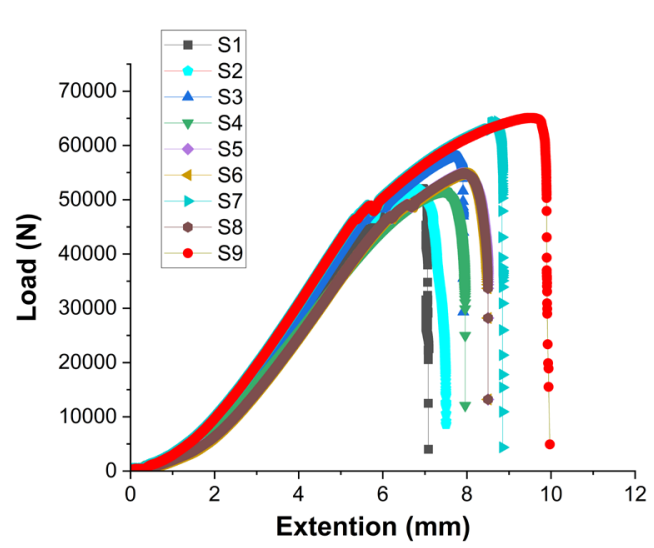

Figure 5. Load vs extension curves of samples.
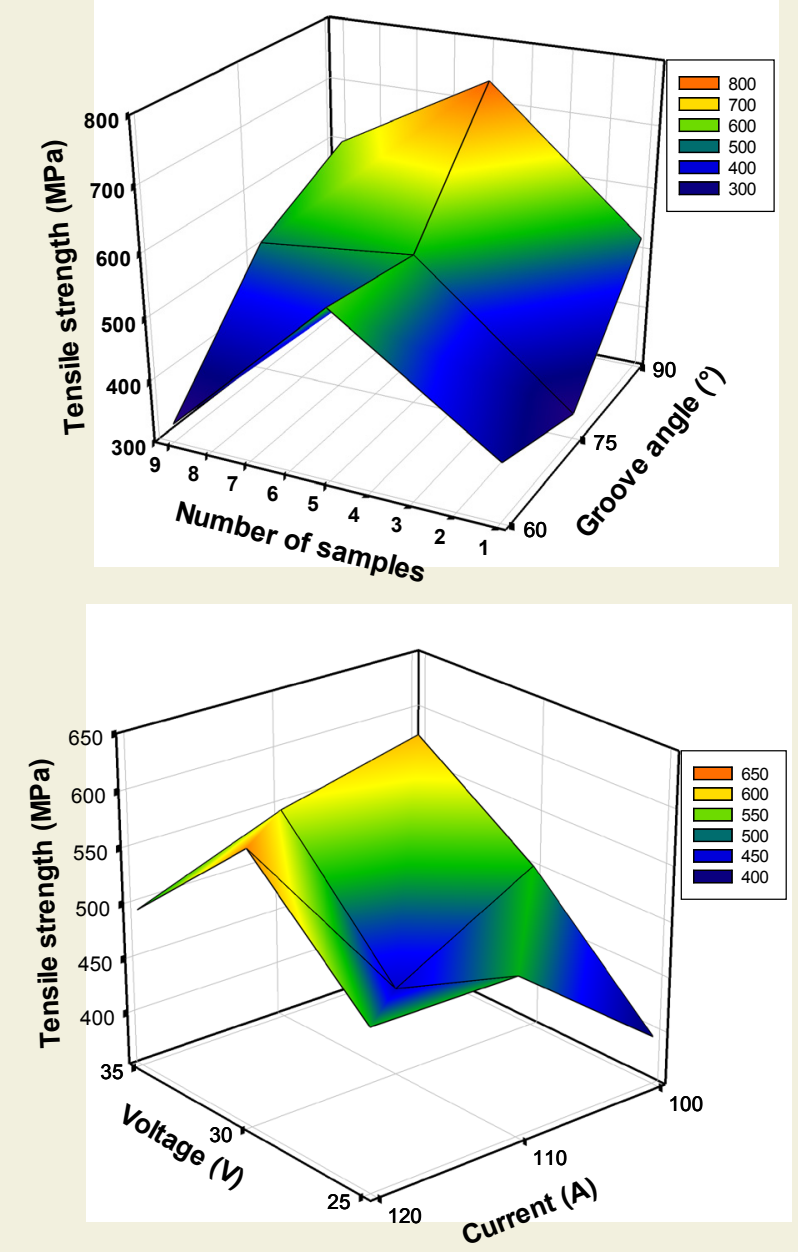

Figure 6. The Effect of welding parameters on tensile strength.

values tend to increase depending on the increase in the trough angles. In the tensile tests of the joints, the tensile strength value of the $90^{\circ}$ groove angled S9 sample was $20.73 \%$ higher than the tensile strength value of the $60^{\circ}$ groove angled S3 sample.

As can be seen in Table 8 and Fig. 7, when the tensile test results of the joints joined by MIG welding are examined, the highest elongation as $11.551 \%$ was obtained at 
Table 8. Experimental results as per Taguchi L9 O.A.

\begin{tabular}{ccccccc}
\hline $\begin{array}{c}\text { Sample } \\
\text { No }\end{array}$ & Groove angle $\left(\alpha^{\circ}\right)$ & Welding technology & Current $(\mathbf{A})$ & Voltage (V) & $\begin{array}{c}\text { Tensile Strength (MPa) } \\
\text { Elongation (\%) }\end{array}$ \\
\hdashline S1 & $60^{\circ}$ & MIG (GMAW) & 100 & 25 & 395.125 & 8.354 \\
S2 & $60^{\circ}$ & MIG (GMAW) & 110 & 30 & 431.199 & 8.752 \\
S3 & $60^{\circ}$ & MIG (GMAW) & 120 & 35 & 495.287 & 9.221 \\
S4 & $75^{\circ}$ & MIG (GMAW) & 100 & 30 & 501.234 & 9.031 \\
S5 & $75^{\circ}$ & MIG (GMAW) & 110 & 35 & 545.299 & 10.011 \\
S6 & $75^{\circ}$ & MIG (GMAW) & 120 & 25 & 497.325 & 9.495 \\
S7 & $90^{\circ}$ & MIG (GMAW) & 100 & 35 & 576.997 & 10.949 \\
S8 & $90^{\circ}$ & MIG (GMAW) & 110 & 25 & 495.945 & 9.989 \\
S9 & $90^{\circ}$ & MIG (GMAW) & 120 & 30 & 597.963 & 11.551 \\
\hline
\end{tabular}

groove angle $90^{\circ}$, current $120 \mathrm{~A}$ and voltage $30 \mathrm{~V}$. In the tests, the lowest elongation was measured as $8.354 \%$. The results showed that the highest elongation was $38.30 \%$ higher than the lowest elongation value. In addition, the average elongation of joints welded by MIG welding was measured as $9.706 \%$.

As seen in Table 8, it has been observed that the tensile

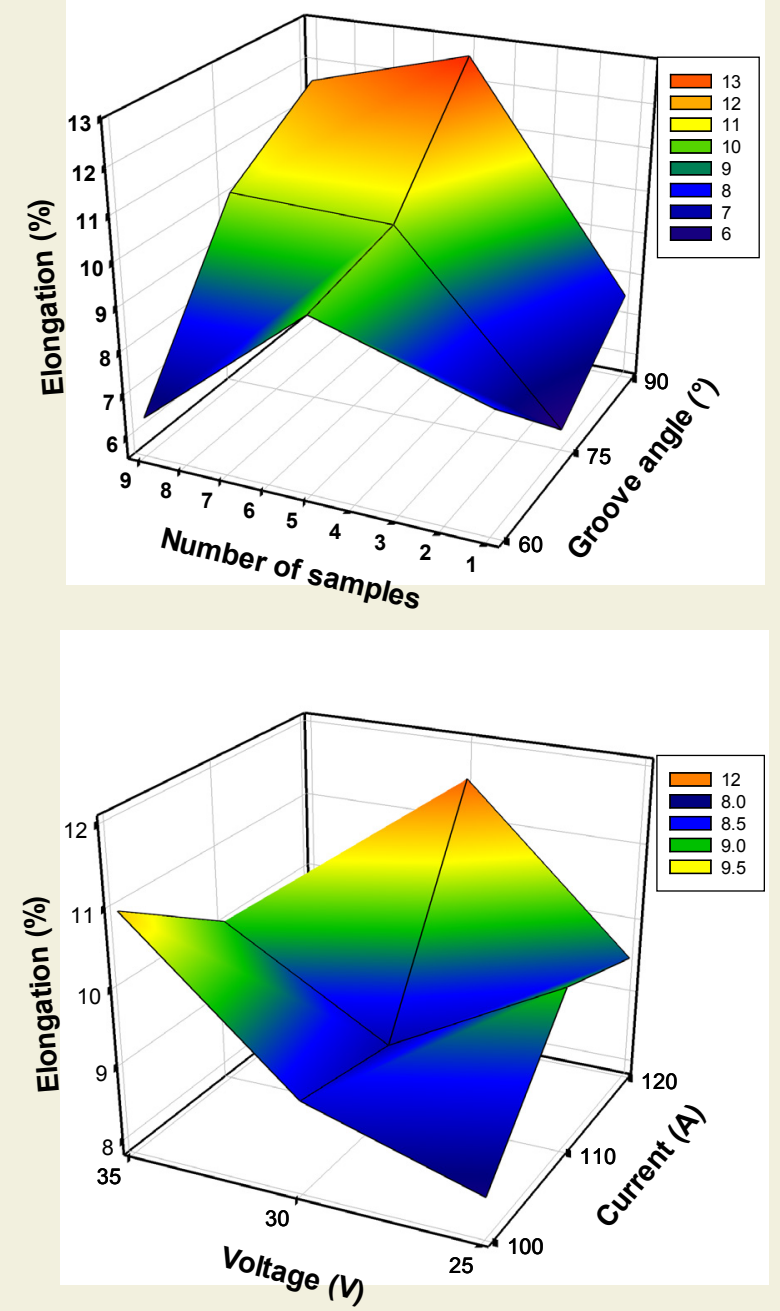

Figure 7. The Effect of welding parameters on elongation. strength and elongation values are generally positively affected by the welding parameters current and voltage increase. In addition, it has been seen that the increases in the tensile strength value due to increasing current and voltage are compatible with previous studies in the literature $[12,13,20,33]$.

\subsection{Analysis of Signal-to-noise $(\mathrm{S} / \mathrm{N})$ ratio}

Experimental design was performed using the Taguchi method in tensile tests. $\mathrm{S} / \mathrm{N}$ ratios were used to optimize control factors $[4,28,31]$. The $S / N$ ratios of the data obtained for tensile strength and elongation are given in $\mathrm{Ta}-$ ble 9 .

As can be seen in Fig. 8 and Fig. 9, the effects of control

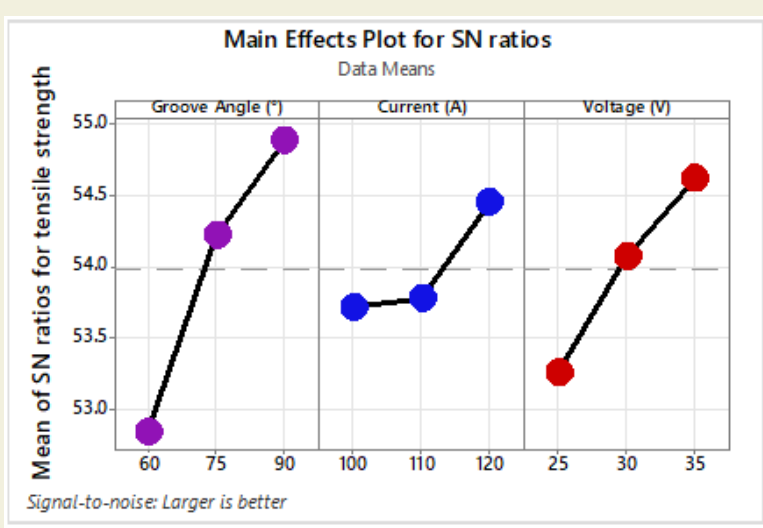

Figure 8. Main effects plot for $\mathrm{S} / \mathrm{N}$ ratios (for tensile strength).

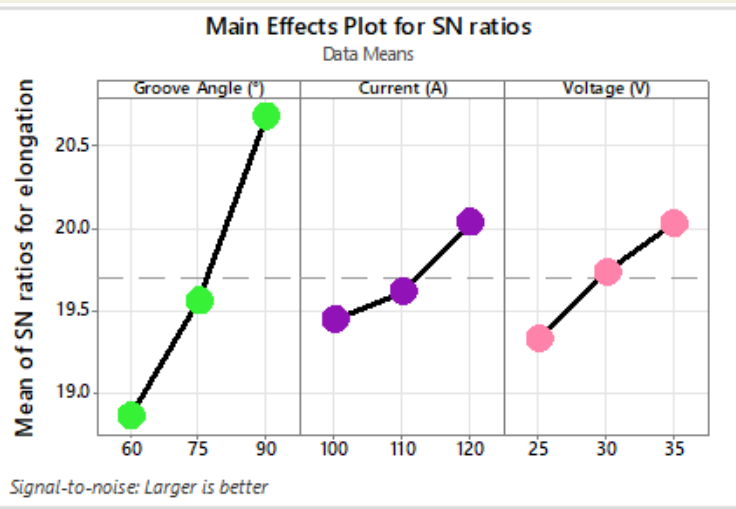

Figure 9. Main effects plot for $\mathrm{S} / \mathrm{N}$ ratios (for elongation). 
Table 9. Response table for $\mathrm{S} / \mathrm{N}$ and significance for tensile strength and elongation.

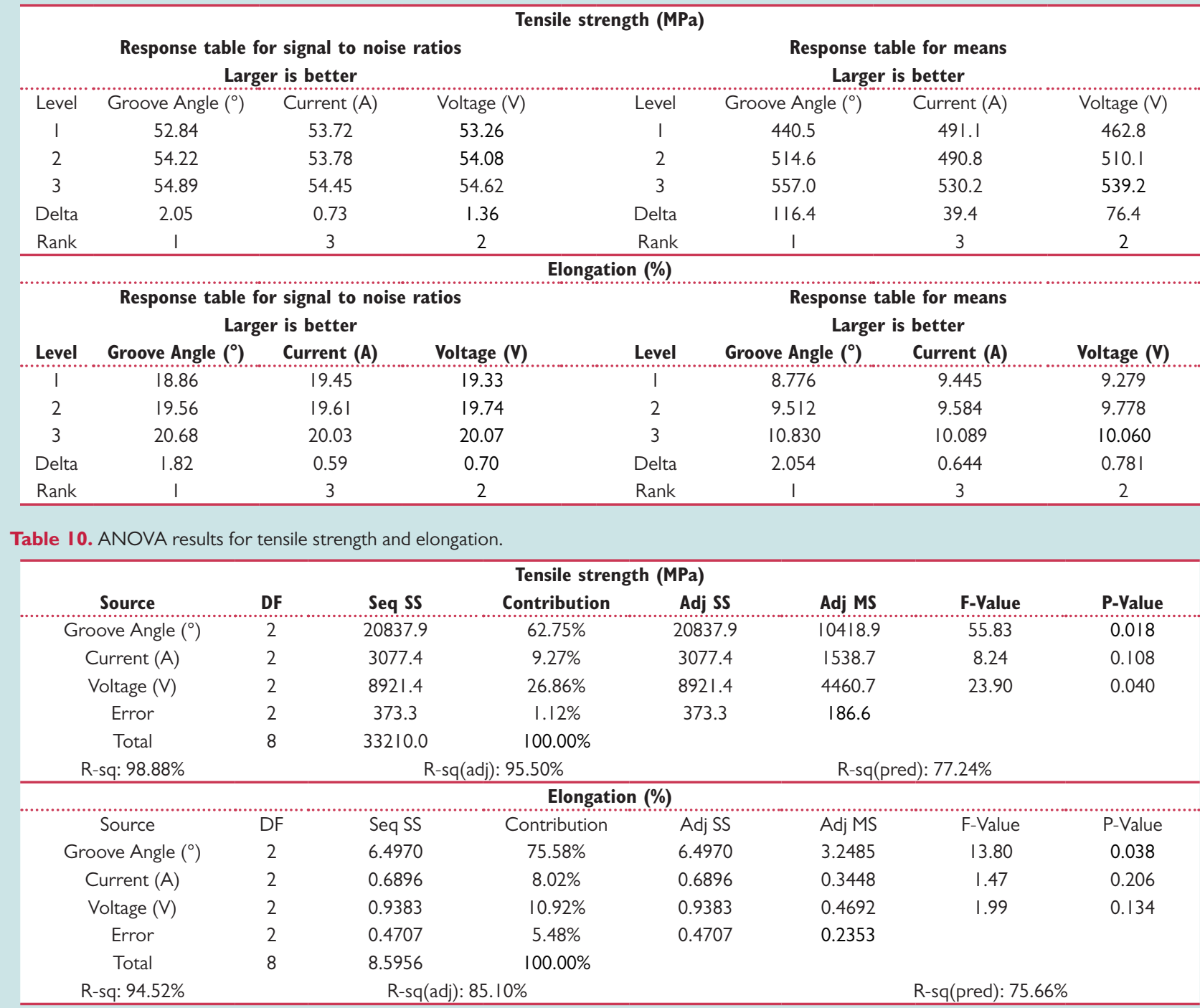

Notes: Adj. SS, Adjusted Sum of Squares; Seq. SS, Sequential Sum of Squares; Adj. MS, Adjusted Mean Squares; P, statistical value; F, statistical test.

factors on the tensile strength and elongation values obtained by the Taguchi method confirm the results obtained from the experimental studies. When the main effects graphs for $\mathrm{S} / \mathrm{N}$ ratios are examined, the values closest to the vertical gain importance. Because these values represent the most effective parameters. Groove angle were seen as the most effective parameters for tensile strength and elongation.

\subsection{Analysis of the variance (ANOVA)}

In this study, the ANOVA was used to analyse the effects of groove angle, current and voltage on damage factors, tensile strength and elongation. This analysis was performed at a 95\% confidence level and 5\% significance level. In the ANOVA analysis, the F values of each control factor are compared and thus the significance of the control factors is determined [4, 28, 31]. The ANOVA analyse results for tensile strength and elongation are given in Table 10.

As can be seen in Table 10, based on the percent additive rates, the most effective factor for tensile strength and elongation was determined to be groove angle. These additive values for tensile strength and elongation were $62.75 \%$ and $75.58 \%$.

\subsection{Analysis of the regression}

Regression analyses are carried out in order to analyse and model different variables that have a relationship between one or more independent variables and a dependent variable $[4,28,31]$. In study, the equations for estimations of tensile strength and elongation were found by regression analysis. Equation estimates were made to be linear models. Estimated linear equations for tensile strength and

\begin{tabular}{ccc}
\multicolumn{3}{l}{ Table I I. Estimated linear equations. } \\
\hline Current (A) & Voltage (V) & Estimated linear equations \\
\hline 120 & 30 & $\begin{array}{r}\text { Tensile Strength (MPa) }=245.2+3.881 \\
\text { Groove Angle }\left(^{\circ}\right)\end{array}$ \\
120 & 35 & $\begin{array}{c}\text { Tensile Strength (MPa) }=274.3+3.881 \\
\text { Groove Angle }\left(^{\circ}\right)\end{array}$ \\
\hline
\end{tabular}

Elongation $(\%)=9.706-0.930$ Groove Angle $\left({ }^{\circ}\right)-0.194$ Groove Angle $\left({ }^{\circ}\right) \_75+$ I. 124 Groove Angle $\left({ }^{\circ}\right) \_90-0.261$ Current (A)_100 - 0.122 Current (A)_1 $10+$ 0.383 Current $(\mathrm{A})$ _ $120-0.427$ Voltage $(\mathrm{V}) \_25+0.072$ Voltage $(\mathrm{V}) \_30+0.354$ Voltage $(\mathrm{V}) \_35$ 


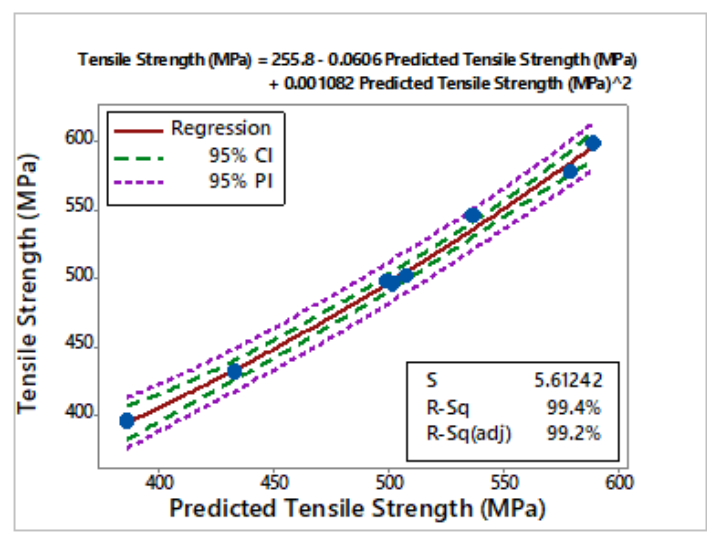

(a)

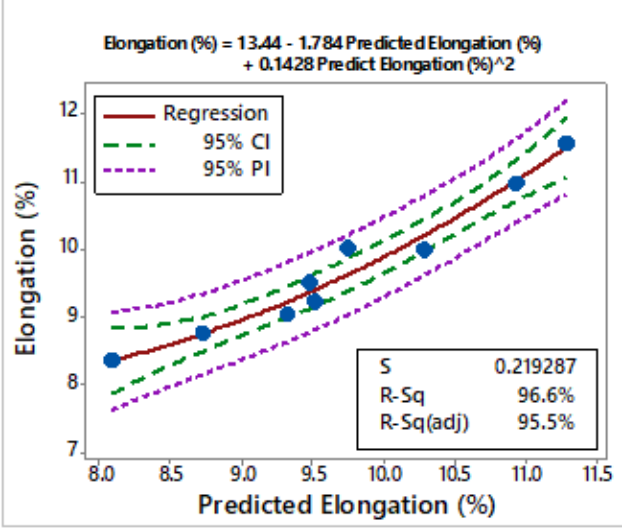

(b)

Figure 10. The experimental results vs predicted values.
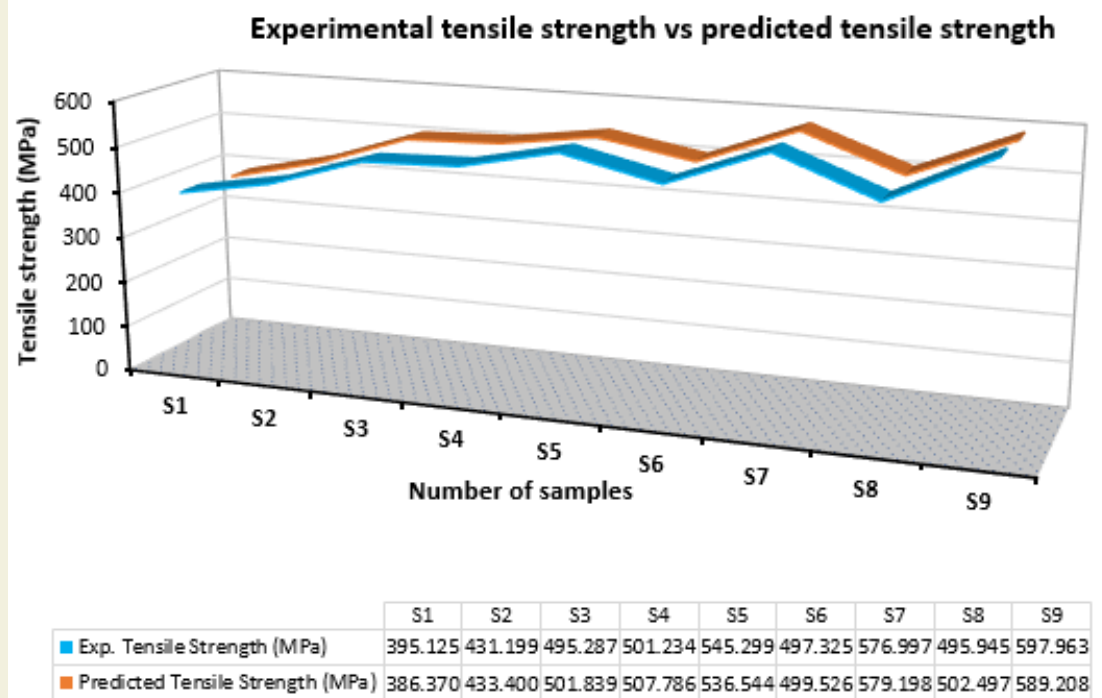

Exp. Tensile Strength (MPa) = Predicted Tensile Strength (MPa)

(a)

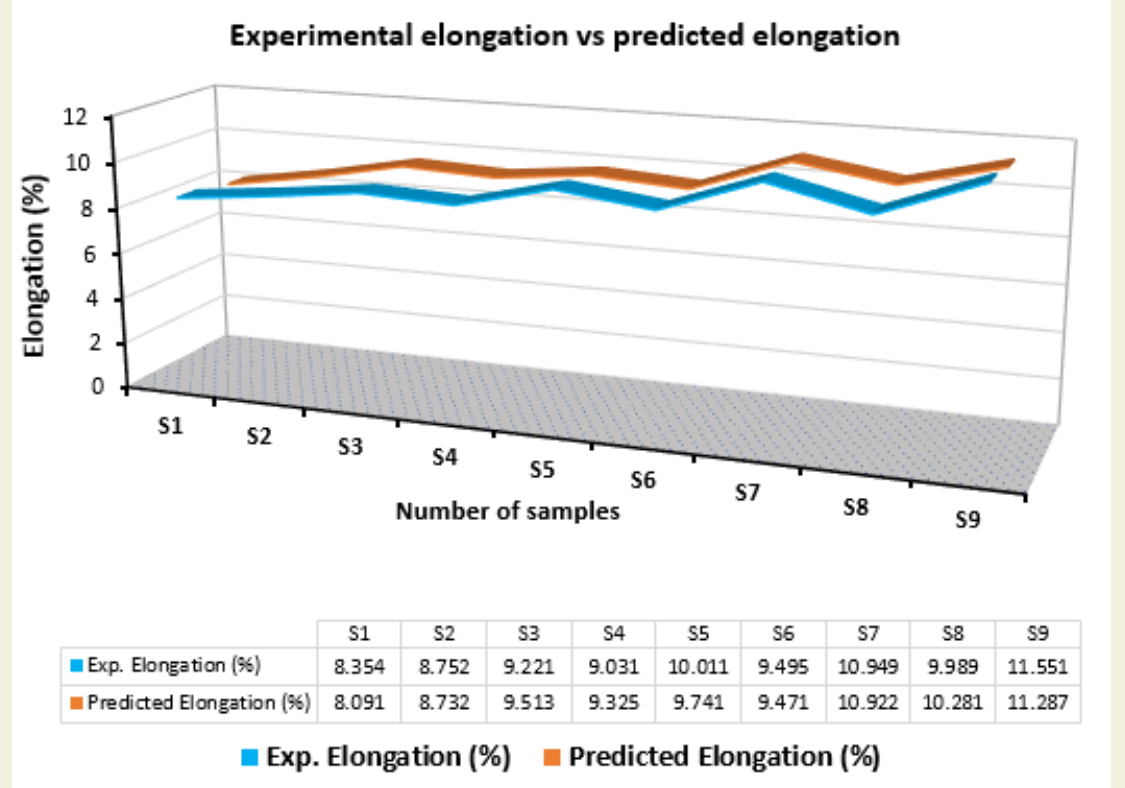

(b)

Figure 11. Comparison of experimental and predicted values for tensile strength and elongation. 
elongation is given in Table 11. As can be seen, the two best equations for tensile strength are shown.

The experimental results versus predicted values for output parameters are given Fig. $10 \mathrm{a}$ and $10 \mathrm{~b}$.

As can be seen in Figures 10 and 10b, a very good correlation was found between the test results and the predicted results. The $\mathrm{R}^{2}$ values of the equations obtained for the average elongation and tensile strength were found to be $96.6 \%$ and $99.4 \%$.

Fig. $11 \mathrm{a}$ and $11 \mathrm{~b}$ show a comparison of experimental values and predicted values for elongation and tensile strength.

\section{Conclusions}

In this study, it was aimed to analyse the tensile strength and elongation of medium carbon steel rod joints joined by MIG welding and to optimize the input parameters with the help of Taguchi method to obtain good mechanical properties. As a result, Taguchi method has been carried out successfully to obtain best MIG welding parameters. The results of the study are given below.

- In the tests, the highest tensile strength as 597.963 MPa was obtained at groove angle $90^{\circ}$, current $120 \mathrm{~A}$ and voltage $30 \mathrm{~V}$. The lowest tensile strength was measured as $395.125 \mathrm{MPa}$. The results showed that the highest tensile strength was $51.33 \%$ higher than the lowest tensile strength value. In addition, the average tensile strength of joints was measured as 504.042 MPa.

- The tensile strength values tend to increase depending on the increase in the groove angles. In the tensile tests of the joints, the tensile strength value of the $90^{\circ}$ groove angled was $20.73 \%$ higher than the tensile strength value of the $60^{\circ}$ groove angled.

- The highest elongation as $11.551 \%$ was obtained at groove angle $90^{\circ}$, current $120 \mathrm{~A}$ and voltage $30 \mathrm{~V}$. The lowest elongation was measured as $8.354 \%$. The results showed that the highest elongation was $38.30 \%$ higher than the lowest elongation value. In addition, the average elongation of joints was measured as 9.706\%.

- the tensile strength and elongation values are generally positively affected by the welding parameters current and voltage increase.

- Based on $\mathrm{S} / \mathrm{N}$ ratios, the optimal parameters for average tensile strength and elongation were $\mathrm{A} 3 \mathrm{~B} 3 \mathrm{C} 2$.

- Based on ANOVA, the most effective parameters on average tensile strength were determined to be groove angle $(62.75 \%)$, followed by voltage $(26.86 \%)$, Current $(9.27 \%)$, respectively. In addition, the most effective parameters on average elongation were determined to be groove angle (75.58\%), followed by volt- age (10.92\%), Current $(8.02 \%)$, respectively.

\section{References}

[1] Kah, P., Suoranta, R., Martikainen, J., (2013). Advanced gas metal arc welding processes. The International Journal of Advanced Manufacturing Technology, vol. 67, no. 1, pp. 655-674.

[2] Kalpakjian, S., Schmid, S.R., (2013). Manufacturing Engineering and Technology, Seventh ed. Pearson Prentice-Hall, Hoboken, NJ, USA.

[3] MillerWelds, (2014). Welding Process Training Series: Introduction to Welding. Miller Electric Mfg. Co., Appleton, Wisconsin, USA.

[4] Ramarao, M., King, M.F.L., Sivakumar, A., Manikandan, V., Vijayakumar, M., Subbiah, R., (2021). Optimizing GMAW parameters to achieve high impact strength of the dissimilar weld joints using Taguchi approach. Materials Today: Proceedings, pp. 1-6.

[5] Cary, H.B., Helzer, S.C., (2005). Modern welding technology, 6th ed. Pearson Prentice-Hall, Upper Saddle River, New Jersey, Ohio, USA.

[6] Kou, S., (2003). Welding metallurgy 2nd edition ed. A John Wiley \& Sons Inc., New Jersey, USA.

[7] Althouse, A.D., Turnquist, C.H., Bowditch, W.A., Bowditch, K.E., Bowditch, M.A., (2020). Modern welding, 12th ed. The Goodheart-Wilcox Company, Inc.

[8] Jeffus, L., (2020). Welding: principles and applications, 9th ed. Cengage, 200 Pier 4 Boulevard Boston, MA, USA .

[9] Kishore, K., Krishna, P.G., Veladri, K., Ali, S.Q., (2010). Analysis of defects in gas shielded arc welding of AISI1040 steel using Taguchi method. ARPN Journal of Engineering and Applied Sciences, vol. 5, no. 1, pp. 37-41.

[10] Patel, R.B.P.D.B., Patel, T.M., (2013). A Review on Experimental Investigation of GMAW for AISI 1045 by using Taguchi Method. International Journal for Scientific Research \& Development, vol. 1, pp. 1679-1682.

[11] Wang, D., Yao, D., Gao, Z., Wang, Q., Zhang, Z., Li, X., (2021). Fatigue mechanism of medium-carbon steel welded joint: Competitive impacts of various defects. International Journal of Fatigue, p. 106363.

[12] Pal, A., (2015). MIG welding parametric optimisation using taguchi's orthogonal array and analysis of variance. International Journal of Research Review in Engineering Science \& technology vol. 4, no. 1, pp. 211-217.

[13] Utkarsh, S., Neel, P., Mahajan, M.T., Jignesh, P., Prajapati, R., (2014). Experimental investigation of MIG welding for ST-37 using design of experiment. International Journal of Scientific and Research Publications, vol. 4, no. 5, pp. 402405.

[14] Narwadkar, A., Bhosle, S., (2016). Optimization of MIG welding parameters to control the angular distortion in Fe410WA steel. Materials and Manufacturing Processes, vol. 31, no. 16, pp. 2158-2164.

[15] Sankar, B.V., Lawrence, I.D., Jayabal, S., (2018). Experimental study and analysis of weld parameters by GRA on MIG welding. Materials Today: Proceedings, vol. 5, no. 6, pp. 14309-14316.

[16] Kumar, P., Roy, B., (2013). Parameters Optimization for Gas 
Metal Arc Welding of Austenitic Stainless Steel (AISI 304) \& Low Carbon Steel using Taguchi's Technique. International Journal of Engineering and Management Research (IJEMR), vol. 3, no. 4, pp. 18-22.

[17] Moghaddam, M.A., Golmezergi, R., Kolahan, F., (2016). Multi-variable measurements and optimization of GMAW parameters for API-X42 steel alloy using a hybrid BPNNPSO approach. Measurement, vol. 92, pp. 279-287.

[18] Arya, D.M., Chaturvedi, V., Vimal, J., (2013). Application of signal to noise ratio methodology for optimization of MIG welding process parameters. International Journal of Engineering Research and Applications, vol. 3, no. 4, pp. 1904-1910.

[19] Patil, S., Waghmare, C., (2013). Optimization of MIG welding parameters for improving strength of welded joints. International Journal of Advanced Engineering Research and Studies, pp. 14-16.

[20] Mishra, B., Panda, R., Mohanta, D., (2014). Metal Inert Gas (MIG) welding parameters optimization. International Journal of Multidisciplinary and Current Research, vol. 2, no. 1, pp. 637-639.

[21] Liu, Q., Tian, Y., Zhai, J., Tian, L., Chen, L., Chen, L., (2020). Prediction of Surface Wrinkle Defect of Welding Wire Steel ER70S-6 in Hot Bar Rolling Process Using Finite Element Method and Experiments. Metals, vol. 10, no. 11, p. 1559.

[22] ASME, (2015). Boiler and Pressure Vessel Code: An International Code (2017) Section II Materials Part C Specifications for Welding Rods, Electrodes, and Filler Metals. ASME Boiler and Pressure Vessel Committee on Materials. Two Park Avenue, New York, NY, 10016, U.S.A.

[23] Deepak, J., Raja, V.B., Arputhabalan, J.J., Kumar, G.Y., Thomas, S.K., (2019). Experimental investigation of corten A588 filler rod for welding weathering steel. Materials Today: Proceedings, vol. 16, pp. 1233-1238.

[24] Hoffman, D.J., Dahle, K.R., Fisher, D.J., (2017). Welding. Published by Pearson India Education Services Pvt. Ltd., India, p. 113.

[25] Adin, H., Doğan, A., Adin, M.Ş., (2021). Şehir İçi Doğalgaz Borularındaki Kaynak Hatalarının Tahribatsız ve Tahribatlı Muayene Yöntemleri ile İncelenmesi. Journal of Scientific, Technology and Engineering Research, vol. 2, no. 1, pp. 4657. (in Turkish)

[26] ASTM, (2008). ASTM-E8/E8M Standard Test Methods for Tension Testing of Metallic Materials. ASTM international, West Conshohocken, PA.

[27] Adin, M.Ş., Okumuş, M., (2021). Investigation of Microstructural and Mechanical Properties of Dissimilar Metal Weld Between AISI 420 and AISI 1018 Steels. Arabian Journal for Science and Engineering, pp. 1-10.

[28] Taguchi, G., (1987). System of experimental design, quality resources, New York, USA.

[29] Frango, T.L., Prabhakaran, M., Sivakandhan, C., Babu, K.V., Vairamuthu, J., (2020). Enhancement of welding strength on Eglin steel using MIG welding process. Materials Today: Proceedings, vol. 33, pp. 4617-4620.

[30] Baday, Ş., Başak, H., Sönmez, F., (2017). The assessment of cutting force with taguchi design in medium carbon steelapplied spheroidization heat treatment. Measurement and Control, vol. 50, no. 4, pp. 89-96.

[31] Montgomery, D.C., (2017). Design and analysis of experiments, Ninth ed. John wiley \& sons.

[32] Gürbüz, H., Emre Gönülaçar, Y., (2021). Optimization and evaluation of dry and minimum quantity lubricating methods on machinability of AISI 4140 using Taguchi design and ANOVA. Proceedings of the Institution of Mechanical Engineers, Part C: Journal of Mechanical Engineering Science, vol. 235, no. 7, pp. 1211-1227.

[33] Naveenkumar, S., SooryaPrakash, D.K., Gokilakrishnan, G., Kamalesh, N., (2014). Parametric Optimization Of Welding Process Of Low Carbon Steel (AISI 1019) By Using Taguchi's Approach. International Journal For Technological Research In Engineering, vol. 1, pp. 415-425. 